\title{
Second-Line Chemotherapy in Advanced Non-Small Cell Lung Cancer (NSCLC): Single Institution Experience
}

\author{
Hanaa Attia ${ }^{1}$, Noha Y. Ibrahim¹, Soha M. Talima1, Ibrahim B. Elhassan 1,2 \\ ${ }^{1}$ Clinical Oncology Department, Kasr Al-Ainy Center of Clinical Oncology and Nuclear Medicine \\ (NEMROCK), Kasr Al-Ainy School of Medicine, Cairo University, Egypt; ${ }^{2}$ Khartoum Breast Care \\ Centre, Khartoum, Sudan.
}

\begin{abstract}
Background: Lung cancer is the leading cause of cancer-related death worldwide. Non-small cell lung cancer (NSCLC) accounts for $80-85 \%$.

Methods: In this retrospective hospital based study, 424 NSCLC patients "stage IIIb-IV" were enrolled to analyze the prognostic factors and survival after receiving second-line chemotherapy.

Results: From 424 NSCLC patients, 236 (55.7\%) had stage IIIb-IV disease. The majority (70\%, 165/236) of these patients received best supportive care only and 30\% (71/236) received first-line chemotherapy. Second-line chemotherapy was administered in $11.9 \%$ (28/236) patients after first-line chemotherapy. The median age of patients who received secondline was 58 years. The majority were males (64\%). Sixty four percent had stage IV, 57\% had an Eastern Cooperative Oncology Group (ECOG) performance status of $2-3,72 \%$ had a body mass index of $>18.5 \mathrm{~kg} / \mathrm{m}^{2}$ and $57 \%$ had history of smoking. The median overall survival was 13 months (95\% CI: 6.82-19.18). The first-line chemotherapy was platinumbased combination in all patients, and docetaxel was the second-line treatment in half of the patient. The most common side effects were hematological (93\%) and gastrointestinal (78\%). Higher risk of mortality was accompanied with age 4060 years (HR: 5.53, 95\% CI: 1.29-23.7, $\mathrm{p}=0.022$ ) and stage IV (HR: 3.65, 95\% CI: 1.21-11.06, $\mathrm{p}=0.022)$. Multivariate analysis revealed that stage IV had higher risk of mortality than stage IIIb (HR: 3.75, 95\% CI 0.969-14.535, p = 0.056). The platinum-taxane combination added 3 months in the median survival (13 vs. 10 months, $\mathrm{p}=0.4)$.
\end{abstract}

Conclusion: Stage IV and age between 40-60 years had a higher risk of death in NSCLC.

Keywords: Non-small cell lung cancer, Advanced, second-line chemotherapy

Corresponding author: Noha Y. Ibrahim, MD; Kasr Al-Ainy Center of Clinical Oncology and Nuclear Medicine (NEMROCK), Kasr Alainy School of Medicine, Cairo University; Cairo, Egypt; Email: dr.noha11@ @otmail.com Received: 23-December-2016 Revised: 13-January-2016 Accepted: 18-January-2017

\section{INTRODUCTION}

Lung cancer accounts for $14 \%$ of all new cancer ranking the second in both sexes. Non-small cell lung cancer (NSCLC) accounts for $80-85 \%$ of cases ${ }^{1}$. Locally advanced non operable lung cancer carries a poor prognosis $^{2}$.

In recent years, more focus on the genetic background of lung cancer opened the way for more targeted treatments with minimal side effects. The presence of epidermal growth factor receptor (EGFR), anaplastic lymphoma kinase (ALK) or ROS1 gene rearrangement, allow the use of biological agents as afatinib, erlotinib, or gefitinib and crizotinib in the firstline treatment ${ }^{3}$.

It is Important to be aware that this genetic alterations are present in only small percentage of patients. Therefore, for most eligible patients, doublet cisplatinum based chemotherapy, with antibodies against vascular endothelial growth factor remains the mainstay of treatment ${ }^{4}$.

In second-line treatment, docetaxel, pemetrexed and erlotinib revealed better progression free survival and time to progression. Third line treatment is not routinely recommended. Erlotinib is advised if it is not taken before ${ }^{5,6}$

Immunotherapy is a new advent that flares the field of treatments in lung cancer. It shows signs of future success and minimal toxicity. This includes PD-1/PD-L1 blockades, nivolumab, pembrolizumab. However this needs longer follow up especially when combined with other agents ${ }^{7-10}$.

This study was conducted in patients with locally advanced inoperable and metastatic NSCLC receiving second-line chemotherapy. Assessment of tolerability and response to treatment as well as disease free survival and overall survival were analyzed.

\section{METHODS}

This retrospective hospital based study was approved by Ethics Committee of the Kasr Al-Ainy Center of Clinical Oncology and Nuclear Medicine (NEMROCK)

Eligibility criteria included histopathological diagnosis of NSCLC, stage IIIb-IV, initiation of secondline chemotherapy upon disease progression or stationary course disease and receiving at least 3 cycles of chemotherapy during the first-line treatment. 
The following data were collected: age, gender, common symptoms, modalities of diagnosis, histology, TNM stage according to AJCC/UICC TNM staging system ( $7^{\text {th }}$ edition), the Eastern Cooperative Oncology Group (ECOG) performance status at diagnosis, body mass index, smoking status, co-morbidities, date of diagnosis, date of death or last follow up and chemotherapy given.

Overall survival (OS) was defined as the time from the first diagnosis of NSCLC to the date of death or the date of last follow-up. The Kaplan-Meier method was used for survival analysis and multivariate Cox proportional hazard analysis was performed to identify independent predictors of death. A $p$ value of $<0.05$ was considered significant. The analyses were performed with SPSS software (Statistical Package for the Social Sciences IL USA.).

\section{RESULTS}

Among 424 cases of NSCLC patients, the majority was stage IIIb-IV $(55.7 \%, 236 / 424)$. Of them 71(30\%) received chemotherapy and the rest $(70 \%, 165 / 236)$ were subjected to best supportive care including $28 \%$ receiving palliative radiotherapy. Second-line chemotherapy was feasible in $39.4 \%$ (28/71) of patients taking first-line chemotherapy and to $11.9 \%$ (28 /236) of stage IIIb-IV disease (Figure 1).

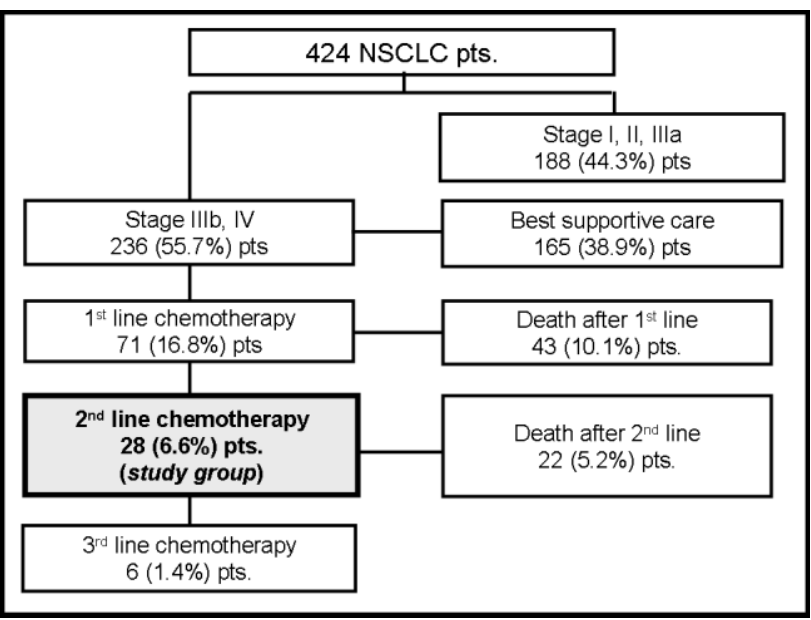

Figure 1: Flow diagram of treatment received by stage IIIb/IV non-small cell lung cancer patients

The clinical characteristics of the 28 patients are listed in Table 1. The median age for all patients was 58 years (range, 37-69 years) and the majority were males $(64 \%)$ and had a BMI of $>18.5 \mathrm{~kg} / \mathrm{m}^{2}(72 \%)$, history of smoking (57\%). The most common co-morbidity was hypertension $(21 \%)$ and the most common symptoms at presentation were cough (93\%) and dyspnea. The most common site of distant metastasis was brain in $21 \%$ of patients followed by bone in $7 \%$.

Details of chemotherapy regimens are listed in Table 2. The first-line chemotherapy was platinum-based combination in all patients with a median number of five cycles. As the first-line treatment, half of the cases received carboplatin-gemcitabine combination.
Table 1: Clinico-epidemiological characteristics of 28 patients with stage IIIb-IV NSCLC receiving second-line chemotherapy

\begin{tabular}{|c|c|c|c|}
\hline & & No. & $\%$ \\
\hline \multicolumn{4}{|c|}{ Gender } \\
\hline & Male & 18 & 64.3 \\
\hline & Female & 10 & 35.7 \\
\hline \multicolumn{4}{|l|}{ Age } \\
\hline & $<40$ & 4 & 14.3 \\
\hline & $40-60$ & 16 & 57.1 \\
\hline & $>60$ & 8 & 28.6 \\
\hline \multicolumn{4}{|c|}{ Performance status } \\
\hline & 1 & 6 & 21.4 \\
\hline & 2 & 14 & 50 \\
\hline & 3 & 2 & 7.1 \\
\hline & Unknown & 6 & 21.4 \\
\hline \multicolumn{4}{|c|}{ Smoking } \\
\hline & Yes & 16 & 57.1 \\
\hline & No & 12 & 42.9 \\
\hline
\end{tabular}

Body mass index

\begin{tabular}{llll}
\hline Underweight & 4 & 14.3 \\
\cline { 2 - 4 } Normal & 2 & 7.1 \\
\cline { 2 - 4 } Overweight & 8 & 28.6 \\
\cline { 2 - 4 } & Unknown & 14 & 50 \\
\hline
\end{tabular}

Co-morbidities

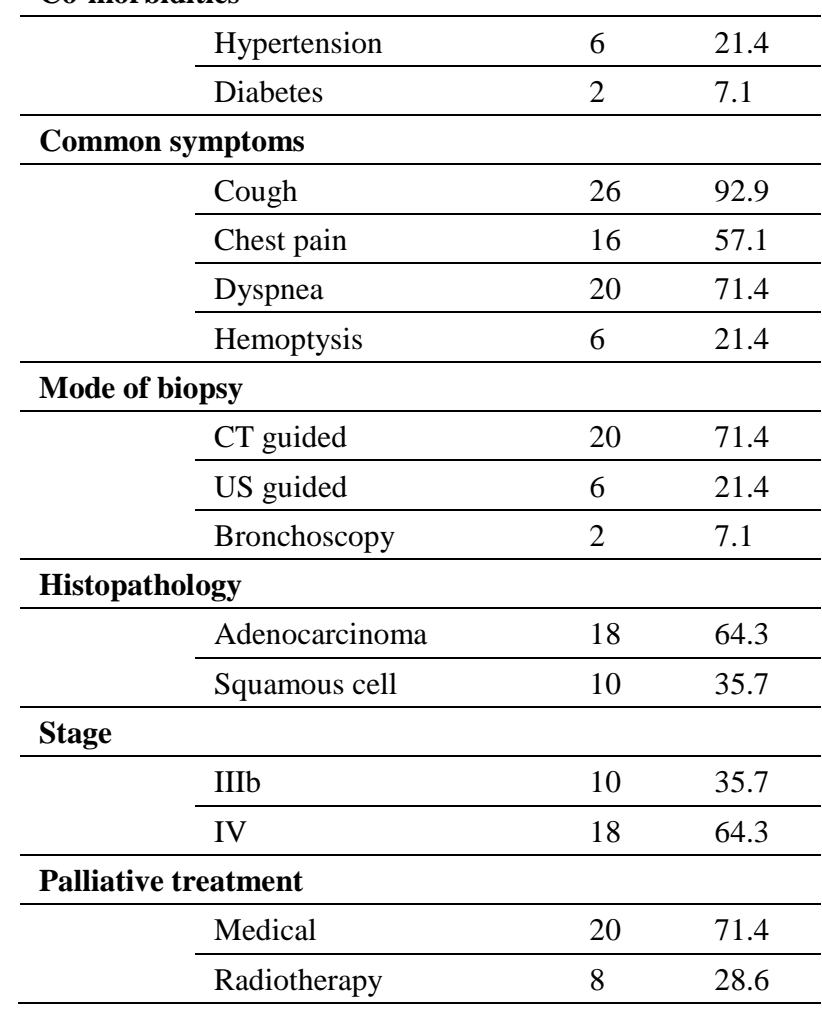

All 28 patients had disease progression and received second-line chemotherapy with a median number of three cycles. Single agent docetaxel was given to $50 \%$ of the patients. The majority of patients $(22 / 28,78 \%)$ had died during the course of second line treatment while 6 $(21 \%)$ progressed and managed to receive third line 
chemotherapy in the form of single agent vinorelbine (4 patients) or paclitaxel (2 patients).

Table 2: Systemic chemotherapy in 28 NSCLC patients

\begin{tabular}{llll}
\hline $\begin{array}{l}\text { Chemotherapy } \\
\text { regimen }\end{array}$ & $\mathbf{1}^{\text {st }}$ line & $\mathbf{2}^{\text {nd }}$ line & $\mathbf{3}^{\text {rd }}$ line \\
\cline { 2 - 4 } $\begin{array}{l}\text { Cisplatin }+ \\
\text { Gemcitabine }\end{array}$ & $8(28.6)$ & $2(7.1)$ & $\mathbf{n}(\%)$ \\
\hline $\begin{array}{l}\text { Cisplatin }+ \\
\text { Navelbine }\end{array}$ & $4(14.3)$ & $2(7.1)$ & \\
\hline $\begin{array}{l}\text { Carboplatin }+ \\
\text { Gemcitabine }\end{array}$ & $14(50)$ & $2(7.1)$ & \\
\hline $\begin{array}{l}\text { Carboplatin }+ \\
\text { Navelbine }\end{array}$ & $2(7.1)$ & & \\
\hline $\begin{array}{l}\text { Carboplatin }+ \\
\text { Paclitaxel }\end{array}$ & & $8(28.6)$ & \\
\hline Docetaxel & & $14(50)$ & \\
\hline Navelbine & & & $4(14.3)$ \\
\hline Paclitaxel & & & $2(7.1)$ \\
\hline
\end{tabular}

During chemotherapy, the most common adverse effect was hematological (93\%) in the form of anemia, neutropenia and thrombocytopenia. Followed by gastrointestinal toxicity in the form of nausea and vomiting observed in $78 \%$ of the patients.

A minority of our patients (7\%) complained of renal toxicity in the form of high serum creatinine and urea. Most of the patients had received palliative treatment (71.4\%), of which $28 \%$ had received palliative radiotherapy (whole brain irradiation in $21 \%$ and bone irradiation in $7 \%$ ).

After a median follow up of 40 months, the median OS was 13 months (95\% CI: 6.82-19.18) shown in Figure 2.

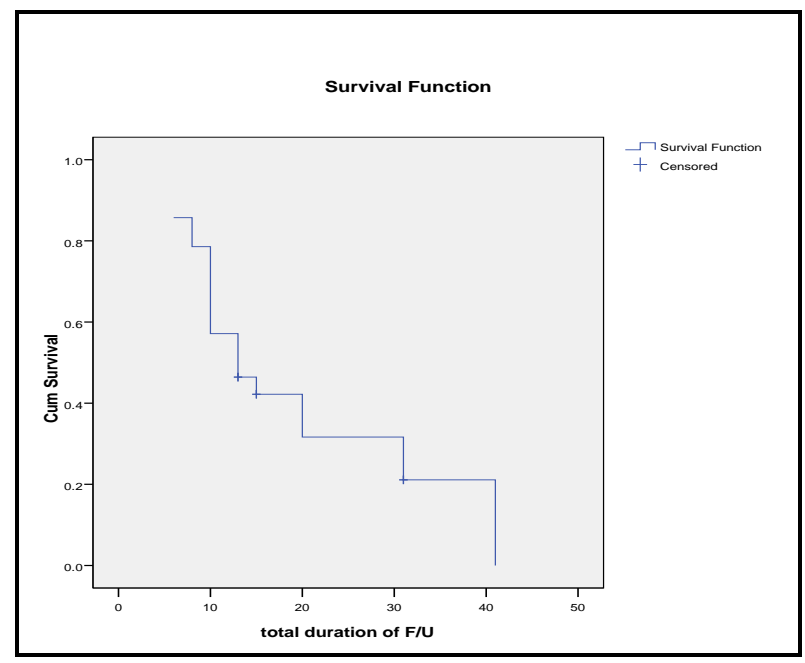

Figure 2: Kaplan-Meier curve: overall survival

Cumulative survival probabilities were estimated using the Kaplan-Meier curve for second-line therapy in patients treated with Platinum/Taxanes in one arm and Platinum + other regimen in the other one. The
Platinum/Taxanes arm added 3 months for the median survival period (13 month vs. 10 months, p-value: 0.4 ) shown in Figure 3.

Patients who received palliative treatment had worse survival (13 vs. 20 months; p-value $=0.886$ ).

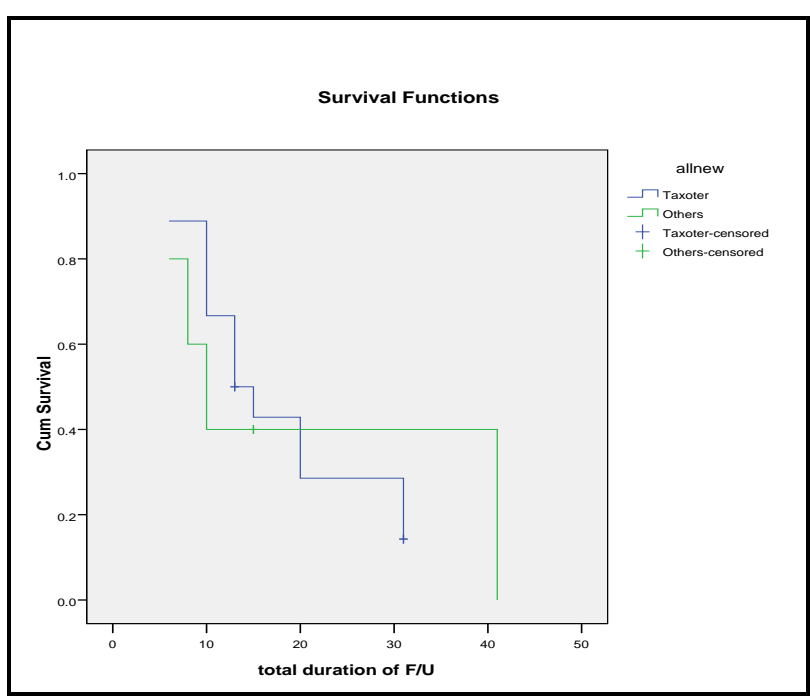

Figure 3: Kaplan Meier overall survival according to second-line chemotherapy: docetaxel $v s$. others

The relation between variables and survival of patients is shown in Table 3. The univariate analysis revealed higher risk of mortality accompanied with the age group 40-60 and stage IV. While in the multivariate analysis, stage IV had a higher risk of mortality (3.752) than stage III.

\section{DISCUSSION}

Our results showed that patients with advanced NSCLC have a higher risk of death mainly with stage IV disease and age between 40-60 years. Better prognosis was shown in cases of non-squamous histology, good nutritional status and in patients received platinum based as first-line treatment followed by taxanes.

The poor prognosis of squamous histology and male gender agrees with Di Maio et al ${ }^{11}$, whereas patients with poor performance status, advanced clinical stage, poor response to first-line chemotherapy, were males and the non-adenocarcinoma histology had worse outcome.

The bad prognosis obtained among patients of the age group 40-60 years was statistically significant in the univariate analysis, however, was contradictory to previous studies comparing adults to older ages. Some studies showed no difference in time to progression and OS between younger and elder patients (>70years) ${ }^{12,13}$. Others obtained a higher risk of death in patients aged 65 and older ones ${ }^{14,15}$. This discrepancy may be attributed to the small sample size of the current study.

The multivariate analysis in this study showed that patients with stage IV disease had a higher risk for death than stage IIIb which is consistent with other studies, whereas the initial clinical stage affects the success of second-line chemotherapy ${ }^{11,14}$. 
Table 3: Prognostic factors by Cox regression analysis

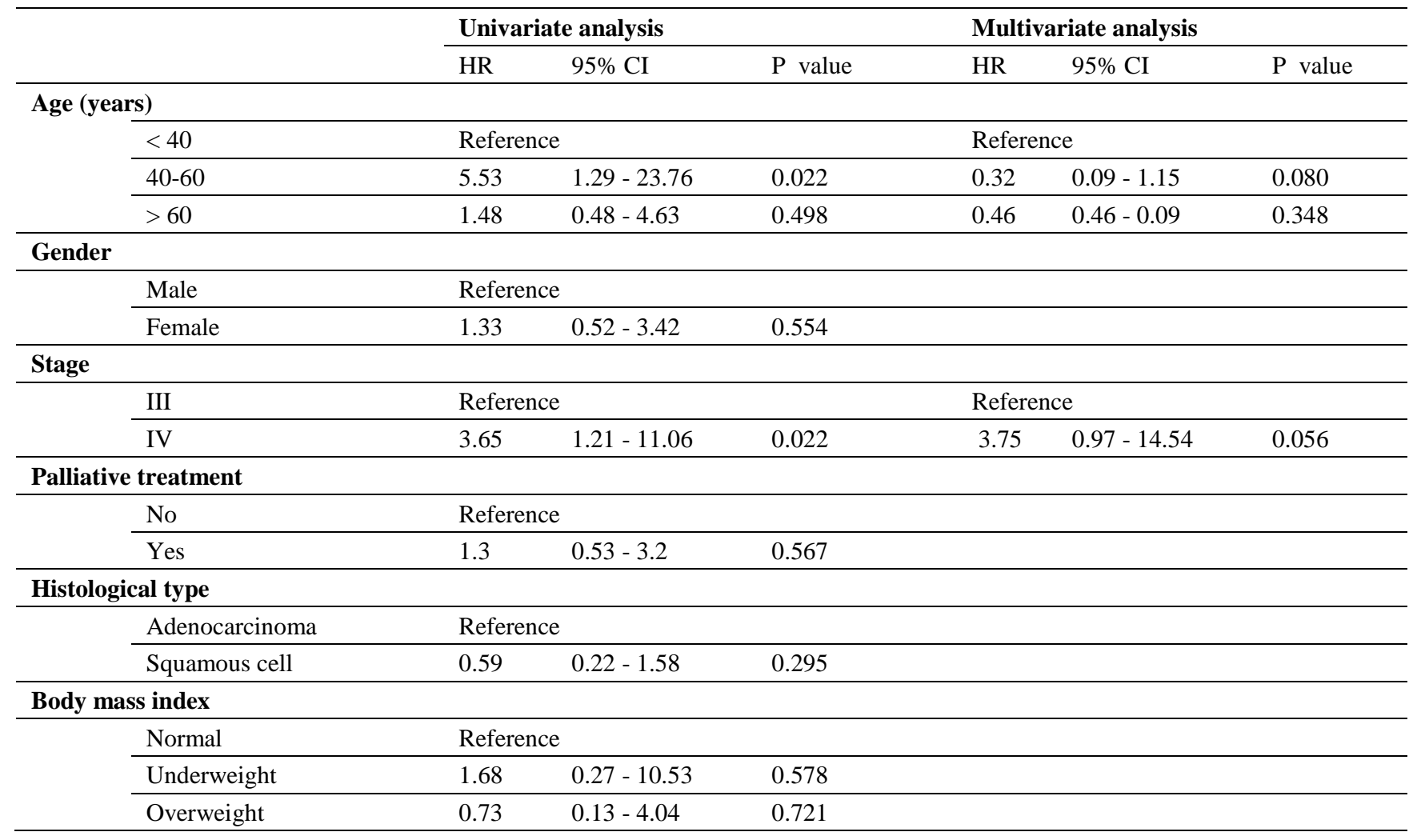

From our study we observed that patients who had received platinum based as first-line treatment followed by taxanes containing regimen as second-line treatment had a better prognosis than others. The taxanes added 3 months to the median survival which was statistically insignificant. Alike some studies reported increase in time to progression (10.6 vs. 6.7 weeks; $p<0.001)$ and median overall survival (7.0 vs. 4.6 months; $p=0.047$ ) in patients receiving docetaxel versus best supportive care 16. Noteworthy, Pemetrexed have been approved in second-line treatment with good tolerability but less effective in squamous histology when compared with docetaxel ${ }^{17-19}$.

Recently, docetaxel, erlotinib and gefitinib are considered as second-line options for NSCLC patients. Pemetrexed is given only to the non-squamous histology. As for $A L K$ rearrangement who experience progression after crizotinib, chemotherapy or ceritinib is given in the second setting. Third line Chemotherapy treatment includes erlotonib if erlotonib or gefitinib were not given. There is limited data to support routine third line 5,6 .

Most of our patients $(71.4 \%)$ received tramadol or morphine as palliative treatment A minority had palliative radiotherapy (28\%), in the form of either whole brain irradiation $(21 \%)$ or bone irradiation $(7 \%)$.

Overall survival analysis indicates that when palliative treatment was initiated patients tend to have a higher risk for death. This can be justified by poor performance of these patients and accompanied with the advanced stage of disease whereas $28 \%$ was metastatic. Body mass index (BMI) is known to reflect the nutritional status, which is an important factor affecting the response to treatment and progression. Although it is not significant, our findings demonstrated that patients with a lower BMI had higher risk of death, which is comparable to Dahlberg et al ${ }^{20}$.

Our study was limited by being a single institutional retrospective study. Another limitation was the small number of cases. Moreover, molecular testing was not performed. Consequently, target therapy and immunotherapy were not offered to this group of patients.

\section{Conclusion}

Advanced NSCLC had a higher risk of death mainly with stage IV disease and age between 40-60 years. Non-squamous histology, good nutritional status and platinum-based first-line treatment followed by taxanes had better prognosis and outcome.

The poor response of second-line chemotherapy in NSCLC encourages introduction of targeted therapy and immunotherapy in this category of patients.

\section{REFERENCES}

1. American Cancer Society's estimates for lung cancer in the United States 2016. http://www.cancer.org/cancer/lungcancer-non-

Smallcell/detailedguide/non-small-cell-lung-cancer.

2. Cicenas S, Zaliene A, Atkocius V. Treatment outcome of locally advanced stage IIIA/B lung cancer. Medicina (Kaunas). 2009; 45(6): 452-459.

3. Reck M, Popat S, Reinmuth N, De Ruysscher, D, Kerr KM, Peters S; ESMO Guidelines Working Group. Metastatic non-small-cell lung cancer (NSCLC): ESMO Clinical Practice Guidelines for diagnosis, treatment and follow-up. Ann Oncol. 2014; 25 (Suppl 3): iii27-39.

4. Chan SK, Gullick WJ, Hill ME. Mutations of the epidermal growth factor receptor in non-small cell lung 
cancer - search and destroy. Eur J Cancer. 2006; 42(1): $17-23$.

5. Masters GA, Temin S, Azzoli CG, et al. Systemic therapy for stage IV non-small-cell lung cancer: American Society of Clinical Oncology clinical practice guideline update. J Clin Oncol. 2015; 33(30): 3488-3515

6. Haspinger ER, Agustoni F, Torri V, et al. Is there evidence for different effects among EGFR-TKIs? Systematic review and meta-analysis of EGFR tyrosine kinase inhibitors (TKIs) versus chemotherapy as first-line treatment for patients harboring EGFR mutations. Crit Rev Oncol Hematol. 2015; 94(2): 213-227.

7. Jing W, Li M, Zhang Y, et al. PD-1/PD-L1 blockades in non-small-cell lung cancer therapy. Onco Targets Ther. 2016; 9: 489-502.

8. Borghaei H, Paz-Ares L, Horn L, et al. Nivolumab versus docetaxel in advanced nonsquamous non-small-cell lung cancer. New Engl J Med. 2015; 373(17): 1627-1639.

9. Herbst RS, Baas P, Kim DW, et al. Pembrolizumab versus docetaxel for previously treated, PD-L1- positive, advanced non-small-cell lung cancer (KEYNOTE-010): a randomised controlled trial. Lancet. 2016; 387(10027): 1540-1550.

10. Schmid-Bindert G, Jiang T. First-line nivolumab (antiPD-1) monotherapy in advanced NSCLC: the story of immune checkpoint inhibitors and "the sorcerers apprentice". Transl Lung Cancer Res. 2015; 4(3): 215216.

11. Di Maio M, Chiodini P, Georgoulias V, et al. Metaanalysis of single-agent chemotherapy compared with combination chemotherapy as second-line treatment of advanced non-small-cell lung cancer. J Clin Oncol. 2009; 27(11): 1836-1843.

12. Weiss GJ, Rosell R, Fossella $F$ et al. The impact of induction chemotherapy on the outcome of second-line therapy with pemtrexed or docetaxelin patients with advanced NSCLC. Ann Oncol. 2007; 18(3): 453-460.

13. Wu Y, Li P, Zhang H, et al. Diagnostic value of fluorine 18 fluorodeoxyglucose positron emission tomography/computed tomography for the detection of metastases in non-small-cell lung cancer patients. Int $\mathbf{J}$ Cancer. 2013; 132(2): E37-E47.

14. Lee SM, Khan I, Upadhyay S, et al. First-line erlotinib in patients with advanced non-small-cell lung cancer unsuitable for chemotherapy (TOPICAL): a double-blind, placebo-controlled, phase 3 trial. Lancet Oncol. 2012; 13(11): 1161-1170.

15. Office for National Statistics. Cancer survival in England: adults diagnosed in 2009 to 2013, followed up to 2014 Newport: Office of National Statistics (ONS), 2015. Available from: https://www.ons.gov.uk/peoplepopulationandcommunity/ healthandsocialcare/conditionsanddiseases/bulletins/cance rsurvivalinenglandadultsdiagnosed/2009to2013followedu pto2014.

16. Shepherd FA, Dancey J, Ramlau R, et al. Prospective randomized trial of docetaxel versus best supportive care in patients with non-small-cell lung cancer previously treated with platinum based chemotherapy. J Clin Oncol. 2000; 18(10): 2095-2103.

17. Hanna N, Shepherd FA, Fossella FV, et al. Randomized phase III trial of pemetrexed versus docetaxel in patients with non-small-cell lung cancer previously treated with chemotherapy. J Clin Oncol. 2004; 22(9): 1589-1597.

18. Peterson P, Park K, Fossella F, Gatzemeier U, JohnW, Scagliotti G. Is pemetrexed more effective in patients with non-squamous histology? A retrospective analysis of a phase III trial of pemetrexed vs docetaxel in previously treated patients with advanced non-small cell lung cancer (NSCLC). Eur J Cancer Suppl. 2007; 5(4): 363-364.

19. Saif Ur Rehman S, Ramalingam SS. Metastatic Lung Cancer: Emerging Therapeutic Strategies. Semin Respir Crit Care Med. 2016; 37(5): 736-749.

20. Dahlberg SE, Schiller JH, Bonomi PB, et al. Body mass index and its association with clinical outcomes for advanced non-small-cell lung cancer patients enrolled on Eastern Cooperative Oncology Group clinical trials. J Thorac Oncol. 2013; 8(9): 1121-1127. 